\title{
Self-sealing Polymeric Materials: Mechanism and Applications
}

\author{
Nand Kumar ${ }^{1, *}$, Dibyendu Sekhar Bag ${ }^{1}$, Krishna Pratap Singh ${ }^{1}$, Akansha Dixit ${ }^{1}$, Shashank Mishra ${ }^{1}$, \\ Durgesh Nath Tripathi', Namburi Eswara Prasad'
}

${ }^{1}$ Defence Materials \& Stores Research and Development Establishment, DMSRDE (DRDO), G. T. Road, Kanpur 208013, India

*Corresponding author: E-mail: nandkkumar60@gmail.com; Tel: (+91) 8447975180

DOI: 10.5185/amlett.2020.061521

Self-sealing polymers possess the virtue to seal small punctures/cracks/damages automatically whenever occurred in the materials/components during their service. This behaviour of self-sealing in polymeric materials is inspired by the biological system in which self-sealing is a usual phenomenon. There are many self-sealing approaches demonstrated by researchers which are being applied in many polymeric components and systems to prevent them from catastrophic failure. The sealant materials in these systems are the main parts which play a crucial role in the sealing phenomenon. This review article describes self-sealing phenomenon, sealant materials and their applications in the various strategic materials and systems namely self-sealing spacecraft structures in the meteoroid environments, self-sealing fuel tank for fighter aircrafts, self-sealing hemostatic syringe to prevent bleeding, self-sealing tires to prevent punctures and concrete structures to prevent water leakages etc.

\section{Introduction and Overview}

Self repairement of the damages is the natural asset of biological systems. Many engineering researches have been carried out to design new materials with such selfhealing/sealing ability. Self-sealing materials exhibit the property to repair themselves and regain their functionality. Whether the process of repairement is automatic or assisted by external factors, the process of recovery is triggered by the damage occurred in the material. Self-sealing materials provide a new path towards safer and durable products and components. The biological system provides abundance of self-sealing phenomenon that guides the principle behind the design and development of their synthetic version. A small number of materials intrinsically possess this capability of self-sealing, and the main focus of this review is to provide an overview strategic materials with self-sealing ability. This is very valuable feature since it effectively enhances the lifetime use of material and has desirable fiscal and human safety traits. In this review, various approaches of self-sealing phenomenon which are being employed in space vehicle applications are examined in section 2, which explores the need and design of selfsealing spacecraft structures in the meteoroid environments for space excursion. Section 3 examines the mechanism of sealing in self-sealing-fuel tank along with the design of sealing membranes, limitations of conventional self-sealing fuel tanks and modern approach of self-sealing technology. Mechanism of prevention of blood loss by self-sealing hemostatic syringe is examined in section 4 in manner to avoid complications occurred due to bleeding in clinical backgrounds, particularly for diabetic patients who experience sluggish hemostasis and for operation proceedings, thereby avoiding plentiful bleeding. Section 5 gives an overview of various investigations regarding the use of self-sealing super absorbent polymers (SAP) for concrete technology, their sealing mechanism, tests to examine self-sealing behavior and mathematical modeling to understand factors influencing sealing of crack with SAP. Last but not the least, section 6 examines the structural design and mechanism of sealing in self-sealing tires. Buoyantly, the reciters of the review are left with some idea of what to do and what not to do while designing the self-sealing polymeric materials.

\section{Self-sealing spacecraft structures in the meteoroid environments}

During the space excursion, a careful attention from the meteoroid environment must be taken because meteoroid encounters and creates various problems to the spacecraft designs. One of them is loss of fluids which affects to the completion of mission. So, for any ambitious projects related to space travel, a structure which provides penetration resistance can only help in completion of the missions. Structural composites utilizing polymeric materials have been designed by researchers reliably which demonstrates a capability of self-sealing compatible with system requirements. There are many approaches of self-sealing employed in the self-sealing technologies in space vehicles which has been described in the sections 2.1, 2.2 and 2.3 [1-5].

\section{Mechanical Self-sealing Approach}

Activation of sealing through mechanical response of elastomeric material

In this approach, activation of self-sealing phenomenon is occurred by the mechanical response of elastomeric material. Here, cells consist of double wall phenolic fiber glass resin honeycomb core sandwiched with cured elastomeric sealing material is used to provide good sealing to core and surface bonding (Fig. 1). The basic 


\section{Advanced Materials Letters www. vbripress.com/aml}

function of honeycomb core is to bestow a damage confinement by addition of bonding surface in the sealant material. Upon puncture by a particle, the dynamic disbalance occurs in the cell which rebounds the confined sealants into the hole and seals the hole.

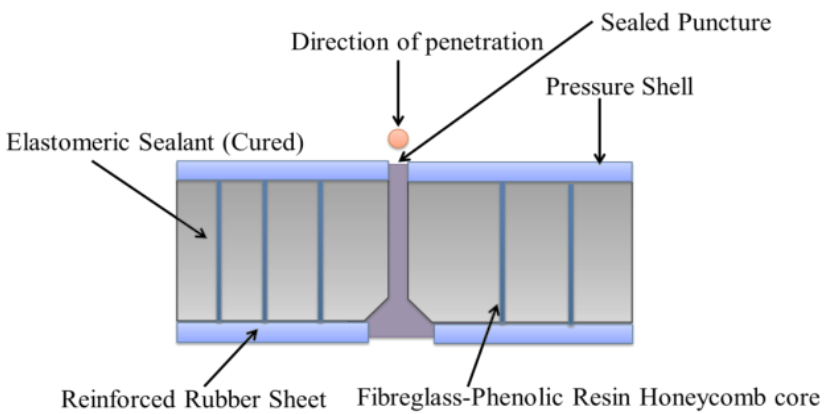

Fig. 1. Self-sealing occurred by the mechanical response of elastomeric sealant material [2].

\section{Activation of sealing through escaping fluid}

The pressure difference created across the puncture in a pressurized compartment generates a force which moves the sealing material into the hole to conclude sealing. This can be done via three ways by using (i) Fiber mat (ii) Elastomer sphere and (iii) Membrane flap.

\section{(i) Sealing by fiber matt}

In this approach, low density asbestos fiber-water mixtures are used as a sealing element. When the pressurized compartment is punctured, fiber-water mixture forms a solid impermeable mass which moves into the puncture due to the pressure difference and thereby seals the hole (Fig. 2).

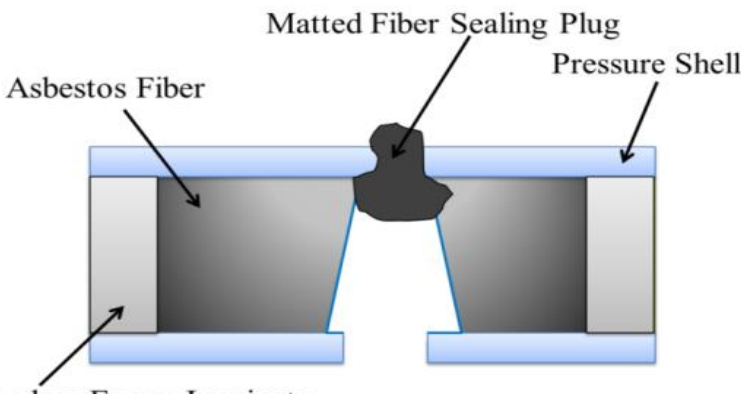

Fiber glass Epoxy Laminate

Fig. 2. Self-sealing by fiber mat concept [2].

\section{(ii) Sealing by elastomer sphere}

The sealing material is basically a flexible impermeable rubber sphere and the effective sealing takes place by the rubber sphere via pressure difference occurred when puncturing is happened (Fig. 3).

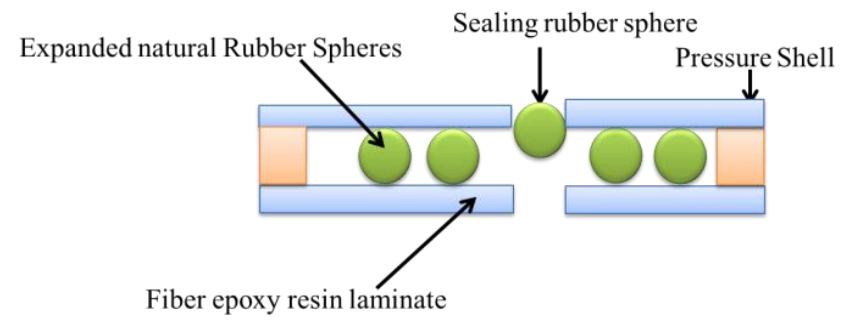

Fig. 3. Self-sealing by elastomer sphere [2].

\section{(iii) Sealing by membrane flap}

The basic configuration, here, consists of an elastomeric material sheet with alternate rows of thin membrane flap segments bulging from one surface while the other surface is bounded to the inside face of pressure shell. The pressure difference across the puncture activates the flap and forces them to close the hole. However, this concept is not so much successful due to the damaging of the flap because of pressure difference or insufficient flexibility of flap membranes.

\section{Chemical self-sealing approach}

\section{Sealing using system of uncured elastomer-catalyst}

Here, a swiftly flowing uncured silicone elastomer is separated from its curing catalyst by a thin impermeable Mylar membrane or by compressing the curing catalyst in Mylar bag. When puncture is occurred, the sealing is done by the formation of solid cured elastomeric plug due to the release of catalyst near to the pellet entry path.

\section{Sealing using system of rigid form resin- catalyst}

In this system, an uncured resin is superseded by a rigid silicon foam resin (Fig. 4). This silicon form resin gets expand when interact with the catalyst and forms a solid sealing plug due to curing. This system is favored over the previous one due to its volume forming ability which allows the interchanging of removed material along the entry path of the pellet, thus assisting the complete sealing of the hole.

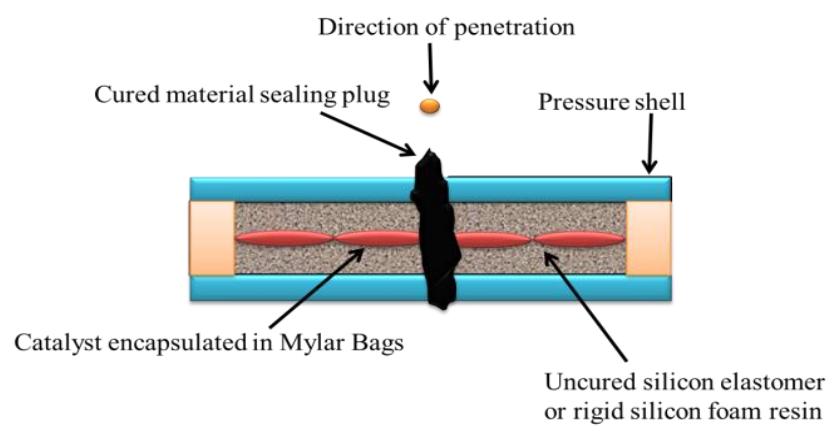

Fig. 4. Self-sealing by chemical approach [2].

The curing of silicon foam resin is based on the hydrosilylation reaction which involves the addition of $\mathrm{Si}-\mathrm{H}$ group to $\mathrm{C}=\mathrm{C}$ bonds. In the usual way, long chained polydimethylsiloxane having two or more vinyl groups reacts with the methyl hydrogen siloxane (crosslinks) in presence of platinum catalyst. The molar ratios of the reactants are the necessary conditions for the optimum curing. Normally 1.5 to 2 times excess $\mathrm{Si}-\mathrm{H}$ groups are taken to get optimum curing. Curing can also be achieved in presence of low temperature peroxides like 2,4-dichlorobenzoylperoxide. The free radical generated from the peroxide abstracts the hydrogen atoms of methyl group of silicone compounds and creates free radical reaction sites. These sites joined together and propagate the crosslinking phenomena (Fig. 5) [6]. 
(i)

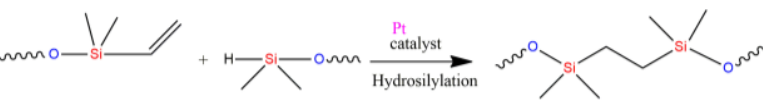

(ii)
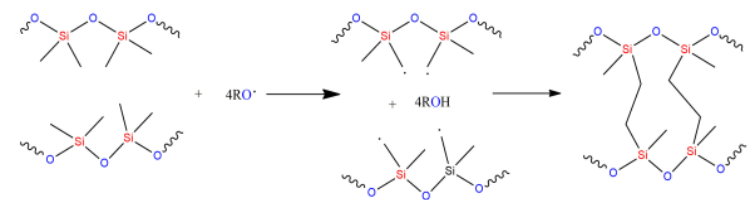

Fig. 5. Curing mechanism of silicon resins in presence of catalyst [6].

\section{Combine mechanical and chemical self-sealing approach}

\section{(i) Sealing by system of combined fiber and chemical}

The elementary components of this approach are shown in Fig. 6. When an impact occurs, loosely packed asbestos fibers partially attenuate the shock waves. Some of the fibers are moved toward the hole while other gets intermixed with the reacting chemical constituents leading to reduction in chemical efflux through the hole until the sealing process is done by the chemical system.

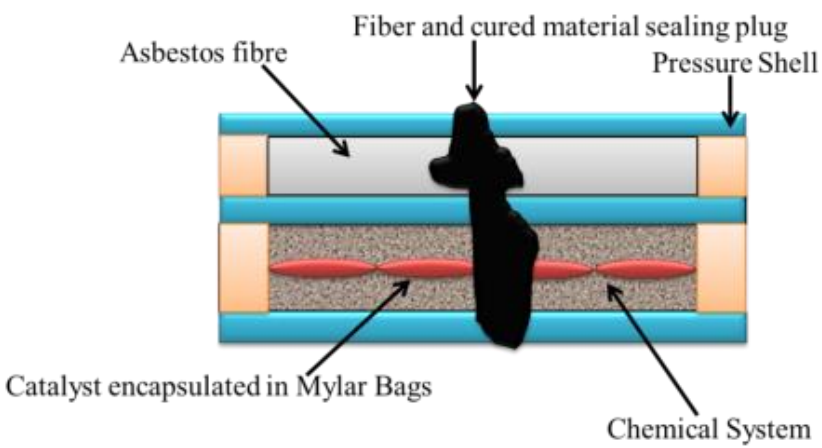

Fig. 6. Self-sealing by combine mechanical - chemical approach (combined fiber and chemical [2]

\section{(ii) Sealing by system of combined rubber spheres and} chemical

Instead of asbestos fibers (as above case), rubber spheres are taken as mechanical sealing elements. The rubber spheres minimize the shock wave due to penetration and perform a partial sealing. Further, a chemical system when comes in contact with catalyst forms a solid mass which completes the sealing action by permanently setting the spheres in the punctured hole (Fig. 7).

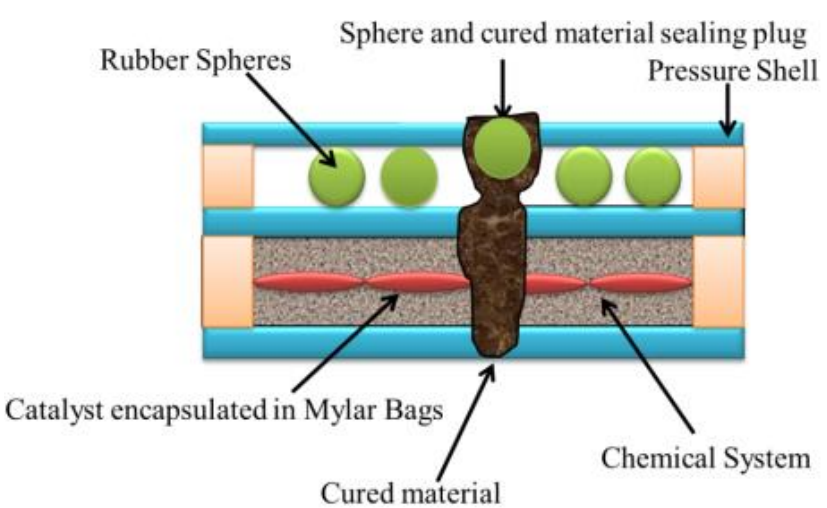

Fig. 7. Self-sealing by combine mechanical - chemical concept (combined spheres and chemical) [2].

\section{Self-sealing fuel tank in fighter aircraft for combat operations}

\section{Fuel Tank}

Fuel Tank is a container which holds the fuel in an aircraft or a motor vehicle. Fuel tanks in the aircrafts can be categorized into two parts based on the position of their installation i.e. internal fuel tanks and external fuel tanks (Fig. 8). Internal fuel tanks are kept inside the aircraft while external fuel tanks are kept outside the aircraft. Further, internal fuel tanks are of four types viz. (i) Integral fuel tank, (ii) Rigid removable fuel tanks, (iii) Bladder fuel tank and (iv) Tip fuel tank. Integral fuel tanks are non-removable in nature and kept in the wings of large aircrafts. While rigid removal fuel tanks are removable in nature and can be made up of metal, plastic or glassfibre. These fuel tanks are installed in the combat aircrafts or helicopters. Self-sealing fuel tanks are such a type of rigid removable fuel tank. On the other hand, bladder fuel tanks are reinforced rubber bags kept inside the high performance light aircrafts. These bladder tanks are protected by the cord or loop in the compartment. While tip fuel tanks are fixed at the end of each wings of aircrafts. Their weight and fuel neutralizes the wing bending loads during the maneuvers and minimizes the strain on the structures. External fuel tanks are also of two types, one is Drop fuel tank and other is conformal fuel tank. Drop fuel tanks are externally mounted auxiliary fuel tanks found in the military aircrafts which are used in the events of emergency. They are normally expandable and jettisonable in nature. Besides this, conformal fuel tanks are the additional tanks snugged closely to an aircraft with restrained aerodynamic penalty juxtapose to the drop fuel tanks [7-9]. Fuel Tank in a fighter aircraft is an important component. It is usually broken or damaged by the enemies attack which not only affects the efficiency but also the journey of that aircraft. It may also catch fire because of fuel leakage from punctures causing an accident.

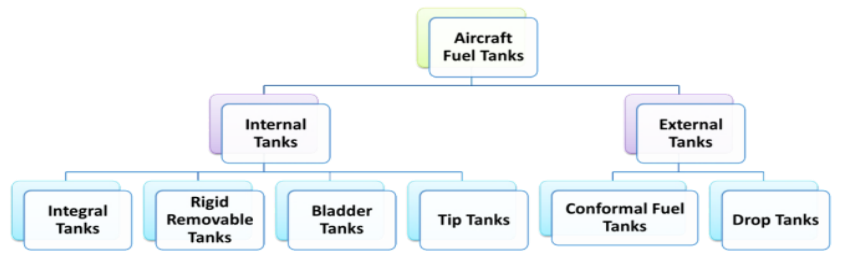

Fig. 8. Different types of aircraft fuel tanks.

\section{Self-sealing fuel tank}

Self-sealing fuel tank, which is a typical rigid removal fuel tank, had been mainly employed in the aviation since World War II to avoid the fuel tanks from seepage of the fuel and catching fire when being damaged by the antagonists. The Henderson Safety Tank company of Elstree, England made a first crash proof self-sealing fuel tank to the miles master trainer aircrafts in the year 1940 [10]. Germans also used self-sealing fuel tanks in their aircrafts using rubber layer over leather skinned with treated fibre in the war against Junker Ju 88 bombers [11]. 


\section{Advanced Materials Letters www. vbripress.com/aml}

Further, Inventor Ernst Eager working in the United states Rubber company designed a self-sealing fuel tank in the year 1941 [12]. A chemist named James Merrill of Goodyear Company (Ohio, U.S.A.) manufactured a selfsealing fuel tank using a double layer system of rubber compounds enclosed in a wing lining of their aircraft in the same year of 1941 [13]. Besides this, the Messerschmitt Me 262 was the first operational jet powered fighter bomber aircraft designed by the Messerschmitt for the Czechoslovak Air Force during the World War II (Fig. 9). This fighter aircraft had also an installed self-sealing fuel tank [14]. Self-sealing fuel tank is mainly consisting of four components: (i) inner fuel/gasoline resistant layer, (ii) a sealing membrane, (iii) an outer cover and (iv) a supporting material.

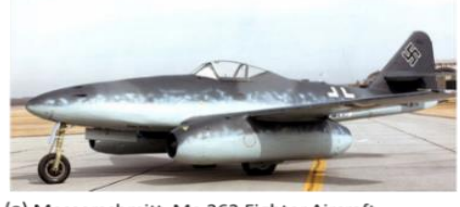

(a) Messerschmitt Me 262 Fighter Aircraft

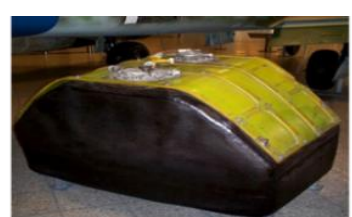

(b) Self-sealing Fuel Tank in Messerschmitt Me Aircraft262 Fighter
Fig. 9. Messerschmitt Me 262 fighter aircraft with its self-sealing fuel $\tan$.

\section{Mechanism of puncture sealing in self-sealing-fuel tanks}

A self-sealing tank is basically a container which automatically seals punctures or damage caused during combat operations. When the bullet infiltrates the outside wall of the cell, the tacky\& elastic sealing material environs the bullet. As the bullet enters into the cell, the sealant springs together quickly and closes the hole. Further some of the fuel in the tank comes in contact with the sealant and makes it swell leading to completion of the sealing process [15]. The process of sealing is shown in Fig. 10.

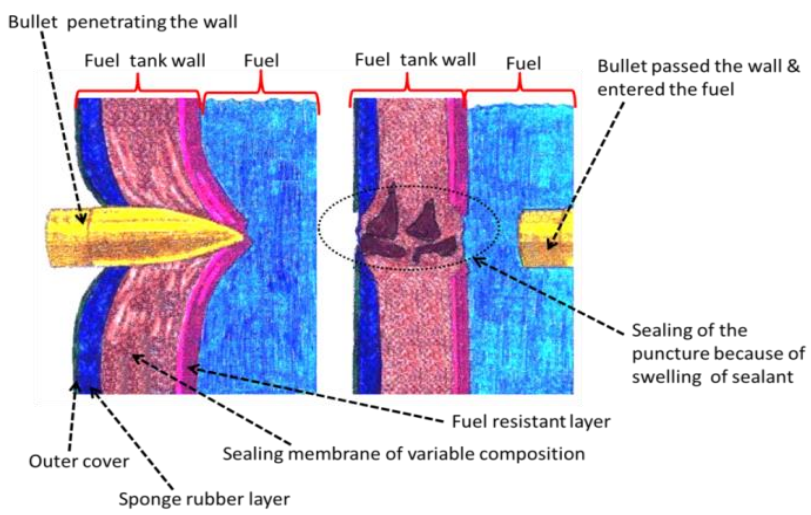

Fig. 10. The bullet is penetrating the wall of the self-sealing fuel tank. The sealing of puncture is occurred through swelling of the sealant material.

\section{Self-sealing polymers used in fuel tanks}

The fuel resistant layer in self-sealing fuel tank could be cellophane or metal foil or any other flexible gasoline resistant material with good strength and resiliency. Polymers like neoprene, poly(vinylphenyl) sulphide, polyimides, poly(vinyl alcohol) plasticized with glycerin, etc. can be used. While a sealing membrane must have rapid swelling quality in fuel as well as good strength with resiliency. Materials like vulcanized rubber, natural and soft synthetic rubbers, various mixtures of unvulcanized rubber with butadiene-acrylonitrile copolymers, copolymer of butadiene-methylpentadiene, etc. can be employed as a sealant membrane. Further, the outer cover of self-sealing fuel tank must be tough and tear resistant material which could be fabrics coated with leather, vulcanized rubber having reinforced pigments, etc. The stiff support material contains the above mentioned parts and it should be made of wood or metal to prevent the sagging and damage of the fuel tank [16-19]. In conventional self-sealing fuel tanks, synthetics like GR-S (Government Rubber Styrene: a copolymer of butadiene and styrene) were used earlier. These synthetics had poor quality swelling rate in fuel as compared to the natural rubber along with their disapproving low temperature properties [20-24]. So, it is obsolete, now-a-days and natural rubber is used as a synthetic for sealing membrane in self-sealing fuel tanks (Table 1).

Table 1. Polymers and their structures used as sealants in the self-sealing fuel tanks.

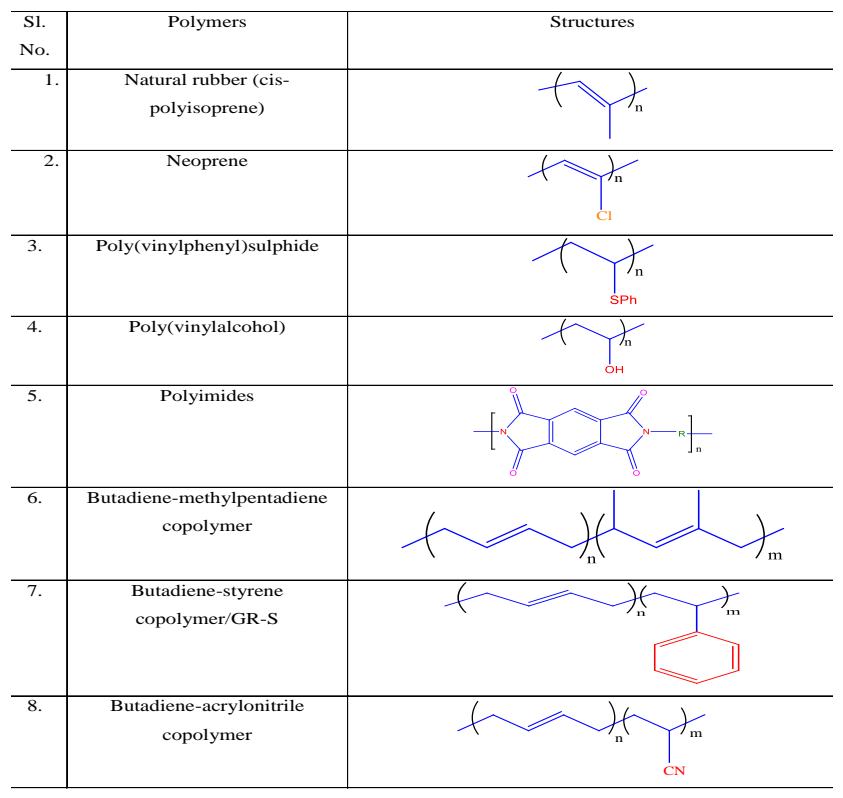

Sealing membrane: How is it made?

A typical sealant membrane is made up of sand wiching several layer sheets (Fig. 11). It consists of a vulcanized neoprene layer sheet (a) of nearly 0.018 inches and another thick layer sheet (b) (0.075 inches) of composition polyisopropylbutylene, polyisobutylene and vulcanized rubber in the ratio 57:13:30. Two of the layers (b) are employed together with the three layers of sheet (a) and adhere to each other. The outer layer is again adhered with the reinforced fabric coated with the neoprene $(0.050$ inches) followed by a rubber sponge which can be made up of leather or vulcanized neoprene. Carbon black can be added to this outer layer to provide maximum possible toughness and tear resistance [25]. 


\section{Advanced Materials Letters www. vbripress.com/aml}

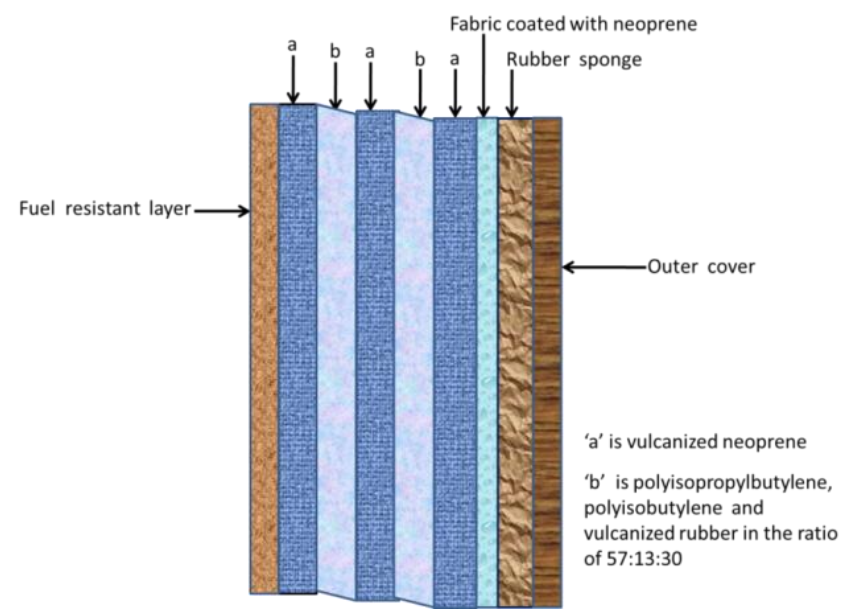

Fig. 11. Structure of a typical sealing membrane.

\section{Self-sealing performance of Korean rotar aircraft fuel tank against gunfire projectiles}

US army have established detailed specification (MILDTL-27422D) which provides information regarding the requirements related to the gunfire projectiles resistant fuel tanks particularly for military rotar aircraft [26-27]. Fuel tank in Korean rotar aircraft has been designed to meet all the necessary requirements mentioned in MILDTL-27422D. This fuel tank showed self-sealing ability which have been established by gunfire resistance test specified in the US specification MIL-DTL-27422D (Fig. 12) [28].

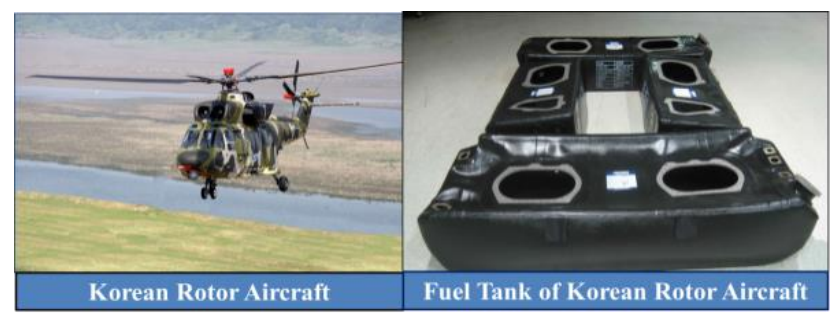

Fig. 12. Korean rotar aircraft with its fuel tank [28].

The fuel tank components in Korean rotar aircraft largely consist of 4 parts. The inner layer which is the innermost part of fuel tank, is made up of rubber. It prevents the penetration of fuel along the fuel barrier for long period of time. Thereafter, Inner reinforced layer made up of rubber coated with fabric is applied for the maintenance. A self-sealing layer made up of special rubber foam is placed between the two reinforced layers of rubber coated with fabric (Fig. 13).

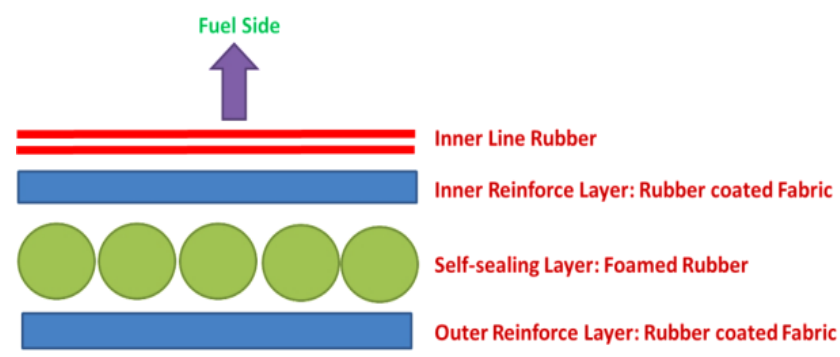

Fig. 13. General structure of Korean self-sealing fuel tank.
Gunfire test was performed on the Korean rotar aircraft self-sealing fuel tank according to US specifications with the self-closure performance requirement for $12.7 \mathrm{~mm}$ armor coat (AP) and $14.5 \mathrm{~mm}$ (area) AP. 10. The test rounds were assigned to one bullet per 15 gallons according to MIL-DTL-27422D and the projectile attack was performed at a distance of $75 \mathrm{ft}$. In addition, the required tangents were applied at different reference speeds in pursuance to the type of bullets $(12.7 \mathrm{~mm} \mathrm{AP} \mathrm{/} 14.5 \mathrm{~mm} \mathrm{AP})$ and were fired in the order according to the projectile area shown in Table 2 . The punctures created by all the bullets were sealed by the sealing action of self-sealing layer. Fig. 14 shows the position and shape of the projected part with respect to each round [28].
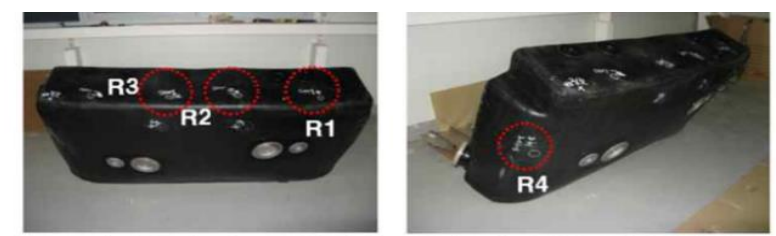

Puncture in the Fuel tank caused by bullets (depicted by R1,R2,R3 \& R4 Circles )

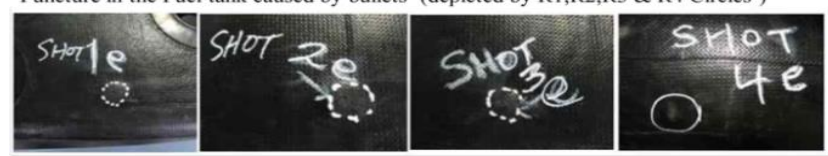

Sealing of the punctures by the sealing action of self sealing Layer in the Fuel tank

Fig. 14. Shows the position and shape of the projected part with respect to each round $[\mathbf{2 8}]$.

Table 2. Test Result of Gunfire Test.

\begin{tabular}{c|c|c}
\hline Sl. No. & Bullet & Domain \\
\hline 1 & $12.7 \mathrm{~mm} \mathrm{AP}$ & $\mathrm{S} / \mathrm{S}$ \\
\hline 2 & $12.7 \mathrm{~mm} \mathrm{AP}$ & $\mathrm{S} / \mathrm{S}$ \\
\hline 3 & $12.7 \mathrm{~mm} \mathrm{AP}$ & $\mathrm{S} / \mathrm{S}$ \\
\hline 4 & $12.7 \mathrm{~mm} \mathrm{AP}$ & $\mathrm{S} / \mathrm{S}$ \\
\hline
\end{tabular}

$* \mathrm{~S} / \mathrm{S}=$ Self Sealing Area

\section{Limitation associated with the conventional self-sealing fuel tank}

The problems associated with the conventional selfsealing fuel tanks using rubber are mainly reduction in the fuel capacity and fuel losses. The rubber layers in selfsealing fuel tanks were thicker which led to the reduction in the capacity of fuel. Fuel losses have been observed by Nakajima Tenzan carrier attack bomber (30\% fuel loss) [29], North American B-25A which faced fuel loss from 912 gallon to 694 gallon (i.e. $23 \%$ fuel drop) [30-31] and P-38D carried self-sealing fuel tanks whose capacity dropped from 410 gallon to 300 gallon (i.e. $27 \%$ lowering in fuel) [32].

Although a provision for installation of 418 gallon tank was made which resulted in slight degradation in the performance of aircraft owing to increase in its weight.

\section{Modern self-sealing approach in self-sealing fuel tank}

An approach, discarding the conventional principle of swelling due to the absorption of fuel, has been recently developed by the SURVICE engineering company. The basic components of modern self-sealing fuel tank are as follows: 


\section{Advanced Materials Letters www. vbripress.com/aml}

(i) Base elastomeric layers: They provide initial mechanical seal to the tank from its exterior.

(ii) Internal liquid reactant layers: They react upon mixing, solidify and expand into damage volumes

(iii) Final elastomeric layers: They block the fuel by mechanical sealing during the reaction.

When a ballistic threat which can be direct or indirect fire impacts the fuel control system, it breaks the first layer which deforms elastically. The threat further breaks the thin layers separating liquid reactants ' $A$ ' \& 'B'. The two liquids flow and mixed together, thereby, inducting the polymerization reaction. The threat exits in the system and first \& last layers rebound elastically. The ' $A$ ' + 'B' reaction proceeds leading to the formation of solid polymer which expands and fills the damaged volumes (Fig. 15) [33].

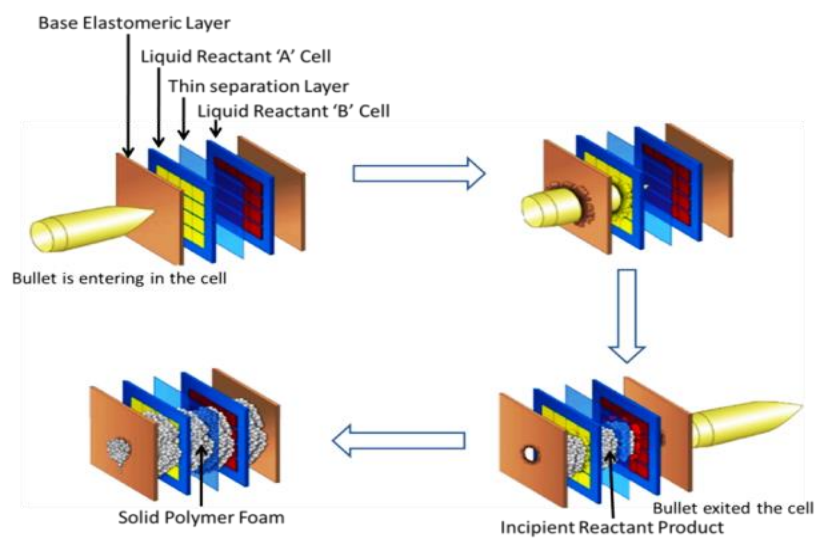

Fig. 15. Pictorial view of modern self-sealing approach developed by SURVICE engineering company [33].

(a)
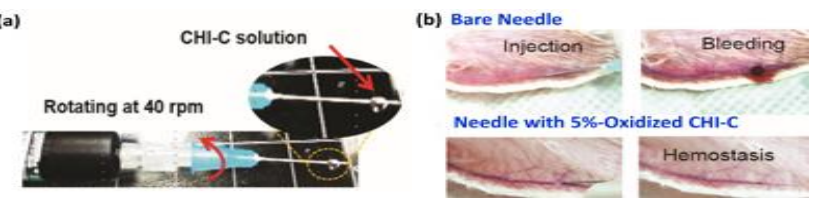

Fig. 16. (a) Preparation of hemostatic syringe (b) Rabbit ear vein bleeding model [34].

\section{Self-sealing hemostatic syringe for prevention of blood loss}

A syringe is commonly used for drug administration, blood sample collection and various surgeries. The bleeding occurred due to puncturing of tissues by the needle of the syringe which results in serious problems related to delayed hemostasis in many of the patients with severe conditions like diabetes, hemophilia or advanced cancer. So, in order to cope up this problem, self-sealing hemostatic needle has been recently reported [34]. In such developments, mussel-inspired catecholamine polymer catechol tethered chitosan (CHI-C) was used to coat on the surfaces of needle of the syringe. It is done by gently placing the drop of CHI-C solution on the needle followed by evaporation to generate polymeric microfilm on needle surface (Fig 16(a)). CHI-C microfilm is mechanically strong and can be easily penetrate to the blood vessels from the skin. But when this microfilm comes into contact with blood, it exhibits self-sealing properties by the sol-gel transformation. This hemostatic needle showed complete prevention of the blood loss in the rabbit ear vein bleeding model (Fig. 16(b)). Loss of blood as a function of time after the injections with bare needles and self-sealing haemostatic needle is provided in Fig. 17 [34]. The bare needle showed rise in blood loss from $0 \mu \mathrm{L}$ to around $840 \mu \mathrm{L}$ within 425 seconds while self-sealing hemostatic syring did not displayed any blood loss due to prevention of blood loss by sol-gel transformation.

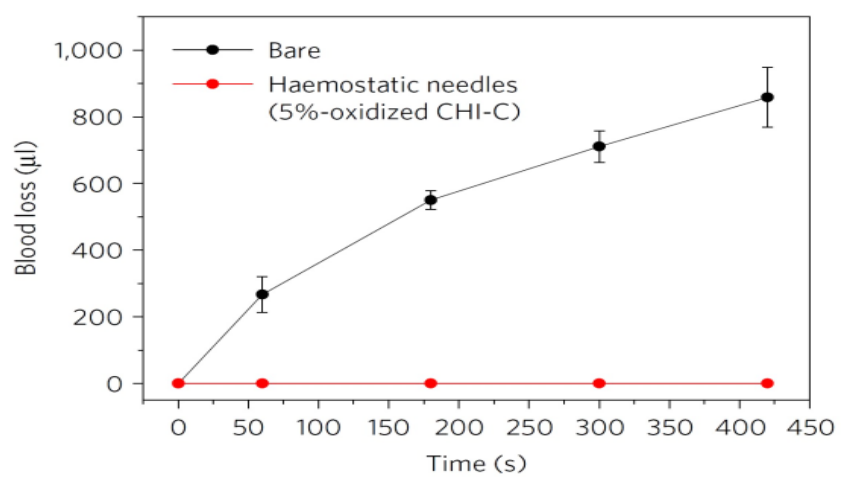

Fig. 17. Rate of blood loss as a function of time for bare and haemostatic needle [34].

\section{Self-sealing Superabsorbent Polymers (SAP) for concrete application}

Cracking of concrete structures is a common problem owing to the intrinsic brittleness of the materials. The damage by cracking seriously affects the integrity as well as durability of the concrete. Cracks cause water leakage, therefore, reduce the functionality of civil structures such as dams, retaining walls, tunnels, reservoirs and waste repositories. Many researchers have long struggled to improve the properties of concrete. Conventional to migrating, these problems including providing better structural design and content proportion of components can help to decrease the probability of cracking and also resin injection of cracks in existing structures [35]. These methods are widely used, but are not always appropriate and sufficient. Now-a-days, superabsorbent polymers are new promising admixtures which are added to cement materials to cater the unavoidable problem arising out in concrete structures [36].

\section{Superabsorbent Polymers (SAP)}

Superabsorbent polymers (SAPs) (also known as hydrogels) are cross-linked polymers which have ability to absorb large amount of water, expanding to form insoluble gels (Fig. 18) [37-40]. The super absorbent polymers are usually composed of charged long chains of polymer networks (partial sodium salt of cross-linked polyacid) which have the capability of absorbing water up to 500 times its original weight and may be up to 2000 times absorption for pure water [41-42]. The volume of gel increases in proportion with the amount of water absorbed [43-44]. Such polymers are widely available commercially. One of the very useful applications of SAP is in agricultural (soil conditioning) application [45-46]. They absorb relatively large amount of water and are 


\section{Advanced Materials Letters www. vbripress.com/aml}

converted it into gel, then slowly releases it with time for farming in deserts. They are also used in slow release of fertilizers, in personal hygiene products (diapers), biomedical (bandages), pharmaceutical (drug delivery), waste solidification and water blocking tapes for undersea cables [47-48].

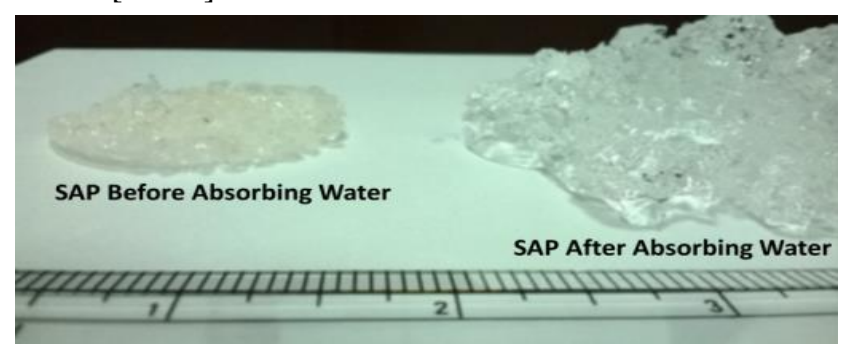

Fig. 18. Super absorbent polymer [37].

\section{SAP in concrete technology}

In concrete technology, [49] superabsorbent polymers are used to supply the hardening concrete with additional water resources for the internal curing. When SAP is mixed with the concrete, it not only improves the water tightening proficiency of concrete but also it offers internal curing moisture and stability to the concrete. This property smoothens the concrete curing processes which are difficult in nature. The superabsorbent polymer is added to the concrete mix absorbs water and consequently transforms it into gels to be released later for the curing process. Excessive amount of superabsorbent polymers added to the concrete mix produces excessive void in the concrete from the hydraulic pressure generated by the concrete mass

\section{Earlier investigations regarding use of $S A P$ in concrete technology}

A comprehensive literature review revealed few significant studies on utilization of superabsorbent polymers in concrete [50-51]. SAP is used as a mixture to enhance water tightening capacities in concrete tanks, retaining structures and aeration basins. The concrete block the water path by semi-solid gels and seals the leakage of water. The bleeding water is reduced with increase in the amount of superabsorbent polymer added to concrete mixture. However, there was an optimum value of superabsorbent polymer which is $0.10 \%$ to the concrete as an admixture for retaining the concrete strength. The increment beyond this optimum amount will affect the strength of concrete negatively. They also proved that the internal curing helps in enhancing the concrete strength [37].

In 2016 [52], the use of polyacrylate as superabsorbent polymer in concrete was studied. In this study, the determination of optimum amount of super absorbent polymer to be added to the concrete was studied in order to improve strength of concrete. Super absorbent polymer ensures very efficient internal water curing by incorporation of a curing agent (an internal reservoir of water) and gradually releasing it when the concrete dries out. Internal water curing has been employed for decades to favor hydration of cement and to control the contraction of concrete during toughening. The increase in strength is relatively small even at the optimum amount in sodium acrylate used in concrete. However, excessive amount of sodium acrylate gives negative effect on the concrete. Best observed compressive strength of super absorbent polymers with concrete is $843.33 \mathrm{kN} / \mathrm{meter}^{2}$ while the super absorbent polymer amount is $0.45 \%$ in 90 days.

In same year, different work on SAP was also done [53], the aim of this work was to investigate the feasibility of superabsorbent polymer as an admixture for self-sealing cracks in concrete. Cracks wider than $0.1 \mathrm{~mm}$ was the main focus of this work because they had limited ability to self-heal naturally which caused leakage and impairing the water tightness of concrete. Many samples with different type of superabsorbent polymer based on partially neutralized acrylates or acrylate/acrylamide copolymers at varying dosages were prepared. A single throughthickness crack, having 0.1-0.4 mm width, was induced in each specimen and then subjected to a flow of $0.12 \mathrm{wt}$. \% $\mathrm{NaCl}$ at hydrostatic pressure gradient of $4 \mathrm{~m} / \mathrm{m}$ to simulate groundwater ingress. Flow was monitored continuously to study the flow rate. The flow rate through samples having cast-in SAP decreased by $85 \%$ to $98 \%$ respectively, comparative to control samples having crack widths. This resulted in the sealing of a $0.3 \mathrm{~mm}$ crack.

The effect of addition of superabsorbent polymer on rheological behaviour of fresh Portland cement-based mortars was reported in the literature [54]. The particle size of SAP influenced their absorption and desorption kinetics. The absorption and desorption of water by SAP in fresh mortar as well as effect of superabsorbent polymer addition on its rheological behavior depended on the availability of free water in the mix. Increasing the waterto-binder ratio resulted in higher water absorption by super absorbent polymer. A research was also performed on the effect of superabsorbent polymer on the characteristics of mortar [55]. The test result showed that flow properties of mortar decreased with increase in superabsorbent polymer volume along with around $31 \%$ improvement in its strength was observed in comparison to plain mortar from this experiment. List of various Superabsorbent Polymers is provided in Table 3.

Table 3. Superabsorbent polymers used in various literatures.

\begin{tabular}{|c|c|c|}
\hline $\begin{array}{l}\text { SI. } \\
\text { No. }\end{array}$ & Super absorbent polymer & Refer-ences \\
\hline 1. & $\begin{array}{lccc}\begin{array}{l}\text { Sodium chloride, } \\
\text { poly }(\text { ethylene glycol) }\end{array} \text { (PEG), SiO2 } & \text { (PNIPA) } & \text { glucose, }\end{array}$ & [32] \\
\hline 2. & $\begin{array}{l}\text { Portland composite cement containing } 27 \% \text { fly ash, polyacrylate or } \\
\text { polyacrylate-co-acrylamide and Sodium Polyacrylate }\end{array}$ & [33] \\
\hline 3. & $\begin{array}{l}\text { Polypropylene fibers, potassium based ionic superabsorbent polymers } \\
\text { with average particle size ranging between } 130-180 \mu \mathrm{m}\end{array}$ & [34] \\
\hline 4. & Poly (Acrylic acid) (AA) and Poly (acrylic acid-co-acrylamide) & [35] \\
\hline 5. & $\begin{array}{l}\text { Acrylamide (AM), N,N,N',N'- Tetramethylethylenediamine } \\
\text { (TEMED), hydrochloric acid (HCI), N,N'-methylene bisacrylamide } \\
\text { (MBA) and sodium hydroxide }\end{array}$ & [36] \\
\hline 6. & Sodium Polyacrylate, polyacrylic acid & [38] \\
\hline 7. & $\begin{array}{l}\text { Sodium alginate, chitosan methacrylic anhydride, sodium hydroxide, } \\
\text { acetic acid, dimethyl amino ethyl methacrylate (DMAEMA) and } \\
\text { dimethylaminopropyl methacrylamide (DMAPMA) }\end{array}$ & [39] \\
\hline 8. & Sodium salt and polyacrylic acid & [40] \\
\hline 9. & Poly ethylene glycol, Acrylamide/acrylic acid copolymers & [41] \\
\hline 10. & Sodium polyacrylic acids polymer, carboxylic acid and acrylates & [42] \\
\hline 11. & Sodium polyacrylate, polyacrylic acid and Basalt rock & [43] \\
\hline
\end{tabular}




\section{Advanced Materials Letters www. vbripress.com/aml}

\section{Mechanism of self-sealing using SAPs}

Superabsorbent polymers may reduce or block permeability of cracked cementations materials as its swelling action physically seals the crack [56]. When liquids enter into a crack, SAP particles along the crack faces swell and block the crack which results in the reduction in water permeability through the crack. In addition to the direct physical blocking effect of swollen SAP, the reduced crack width and flow rate may promote autogenously healing of cracks [57]. These effects would help retain the water-tightness of cracked structures.

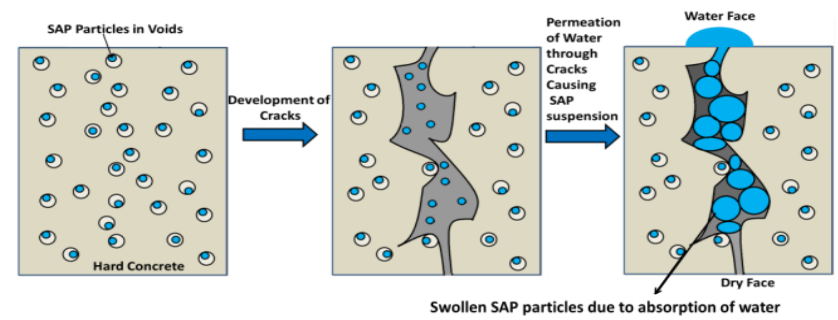

Fig. 19. Schematic diagram of self-sealing mechanism of crack with the help of SAP.

Self-sealing ability of SAPs to heal the cracks in the concretes has been demonstrated in the given model. When the batches of concrete is made, the $\mathrm{pH}$ and the ionic concentrations of mix water is very high (i.e. $\mathrm{pH} 12.5-13$ \& ionic conc. $\sim 150-700 \mathrm{mmol} / \mathrm{L}$ ) when they comes in contact of cement. The ions of the mixture consists of $\mathrm{Ca}^{2}+, \mathrm{K}+, \mathrm{Na}+, \mathrm{OH}-\& \mathrm{SO}_{4}-[\mathbf{5 8}]$. SAP is added in this mixture. The swelling of SAP occurs at very small rate in this mixture as compared to pure water. Further, the formation of bidentate complex between acrylates of SAP and Calcium ions of the mixtures also decrease the swelling of SAP [59-61]. When the cement get hydrated, SAP gradually shrinks due to the release of absorbed water and void of size $10-1000$ microns are created in the cement paste (Fig. 19). When the crack forms in the cement during its service life, it propagates throughout its structure. The SAP lies inoperative in the voids until the cracks occur through the voids. When the concrete undergo wetting, the swelling of SAP occurs due to the absorption of water or external environment fluid. The external fluids have low contents of ions so that reswelling of SAP will take place in significant way. These SAP expands beyond the size of the void and enters into the cracks which leads to healing of the cracks, If the concrete undergoes wetting or drying cycles, the autogenously healing is promoted due to interruption in the water release from SAP [62].

\section{Water flow test}

\section{Sample preparation}

The water flow test is used study the ability of concrete to block the water flow through an induced artificial crack. The sample of the water flow test is of cylindrical shape with its height $10 \mathrm{~mm}$ and diameter $35 \mathrm{~mm}$ (Fig. 20). It is wrecked into two halves and then these equal halves are placed together again. The compiled sample shows a crack in the concrete of $35 \mathrm{~mm}$ width and depth of $10 \mathrm{~mm}$.
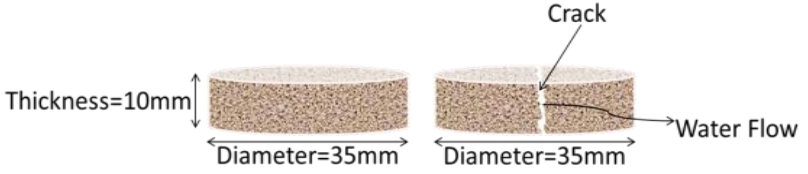

Fig. 20. Size of samples used [63].

There is an optimum amount of superabsorbent polymer that can be added to the plain concrete in order to enhance its strength as well as immovability. Adding more of superabsorbent polymer in the plain concrete not only improves the water tightness property of concrete but also enhances the plasticity of the concerte. A sealant is applied at the boundary of the concrete samples to prevent any leakage. Special mould is used to make the test samples. The fresh concrete is poured into a rubber mould of $10 \mathrm{~mm}$ height and $35 \mathrm{~mm}$ inside dimensions. The concrete top is levelled and smoothened. The edges of each halve were sealed with duct tape to create a barrier for ponding (Fig. 21).
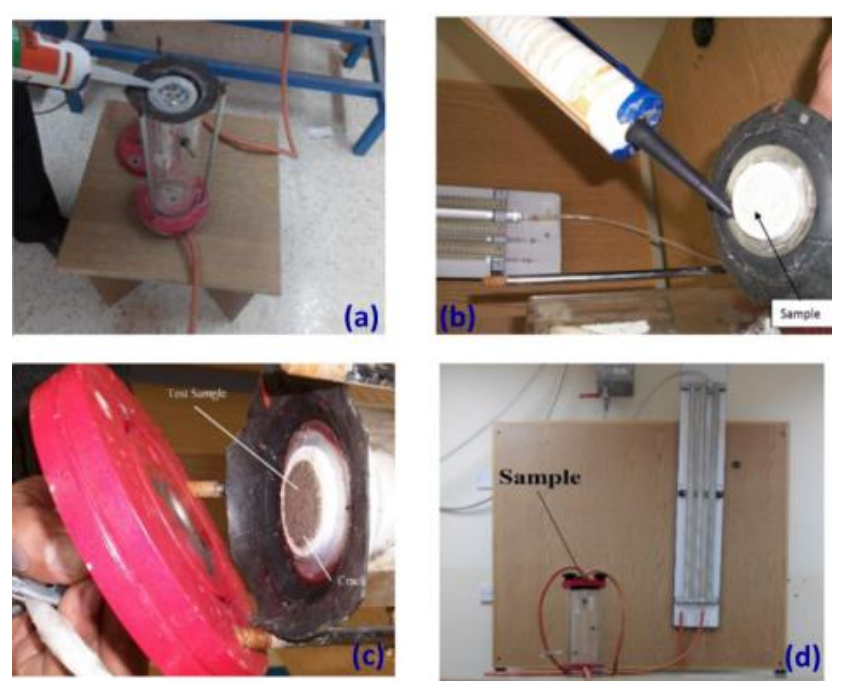

Fig. 21. (a) \& (b) Preparing samples for the test (c) Prepared water flow sample in the testing chamber, and (d) Test set up for falling head and constant head tests [64-66].

In order to maintain moisture in the concrete sample, it is covered in plastic sheets. After this the sample is cured by submerging it in water bath for additional 6 days. The sample is then removed from the water-bath and left to dry for additional 7 days at $50{ }^{\circ} \mathrm{C}$. On the $14^{\text {th }}$ day, water flow test is started in which all the samples are then broken into identical two pieces. The amount of superabsorbent polymer used in this study ranges from different weight of Portland cement.

\section{Performance of water flow test}

The sample for water flow test is placed in the mould and kept in a steel casing which is then placed in testing chamber (Fig. 21(d)). This arrangement must be such that there should be no path for water to flow other than the crack of the concrete. Constant and decreasing water pressure (constant and failing head) is applied to the samples to analyze the sealing capability of the concrete 


\section{Advanced Materials Letters www. vbripress.com/aml}

with water pressure. The measurement of flow of water through concrete is carried out. The amount of water flow indicates the sealing capability of concreate. The lower the quantity of the water flow through concrete, the better will be water tightness capability and better sealing ability of the SAP mixed concrete. The water flow can be calculated by using formula;

$$
\mathrm{Q}=\mathrm{V} / \mathrm{t}
$$

where $\mathrm{Q}$ is the rate of water flow (in $\mathrm{cm}^{3} / \mathrm{min}$ ), $\mathrm{V}$ is the volume of flow of water through the sample $\left(\mathrm{cm}^{3}\right)$ and $t$ is the time taken to drop pressure from $180 \mathrm{~cm}$ to $170 \mathrm{~cm}$ in such a way that total of $31 \mathrm{~cm}^{3}$ of water is discharged [66].

\section{Mathematical modeling to understand factors influencing crack sealing with SAP}

Mathematical modeling can be applied to understand the factors that influence the sealing of crack using SAP. Volume fraction of crack filled $(\varphi)$ can be expressed in terms of width (w), particle size of dry $\operatorname{SAP}\left(\mathrm{d}_{\mathrm{o}}\right)$, SAP dosage ( $\alpha$, mass fraction of cement), initial swelling ratio in cement paste $\left(S_{1}\right)$, and the re-swelling $\operatorname{ratio}\left(S_{2}\right)$ triggered by external fluids. This can be calculated by first determining the mass of SAP exposed in a cement crack, and thereafter estimating the volume of swollen gel that enter into crack, taking account of the initial SAP void volumes. [67].

Let us consider the dry SAP particles are of monosized spheres with diameter $\mathrm{d}_{\mathrm{o}}$ distributed in an arbitrary, inwrought and isotropic manner in the cement paste. When the SAP particle is put into cement, it swells to spheres. It creates a void of diameter $\mathrm{d}_{1}$ when it dries and contracts. The crack is demonstrated as a flat plane that arbitrarily intersects the matrix of cement paste. If propagation of cement crack takes place through a void of SAP, then the SAP particle is exposed to moistening from the external environment. The mass of SAP exposed to moisture per area of cement crack, $\mathrm{mA}$, is given by;

$$
m_{A}=N_{A} X m_{o}
$$

where $\mathrm{N}_{\mathrm{A}}$ is basically the no. of particles per area of cement crack randomly intersect by matrix of cement paste and $\mathrm{m}_{\mathrm{o}}$ is the mass of dry SAP particle. $\mathrm{N}_{\mathrm{A}}$ can be related to $d_{1}$ as

$$
N_{A}=N_{V} d_{1}
$$

where $\mathrm{N}_{\mathrm{V}}$ is the no. of SAP particles per volume of the sample [68-69]. Nv can be related to the concentration of cement, $\mathrm{C}\left(\mathrm{Kg} / \mathrm{m}^{3}\right)$ from mix design as,

$$
N_{v}=\frac{(\alpha C)}{m_{0}}
$$

Now, let us assume that sum of volumes of dry SAP and absorbed solution is equal to the volume of swollen SAP. The diameter of an SAP void $\left(\mathrm{d}_{1)}\right.$ can be written in terms of diameter of a dry SAP particle $\left(\mathrm{d}_{\mathrm{o}}\right)$ as

$$
d_{1}=d_{0} \sqrt[3]{\left(S_{1}\right)\left(\frac{p_{S A P}}{p_{S A P}}\right)+1}
$$

where $p_{S A P}$ is the density of dry SAP and $p_{S A P}$ is the densities of absorbed solution respectively. Substituting (2) \& (4) into Eq. (1) to get the following equation:

$$
m_{A}=C \alpha d_{0} \sqrt[3]{\left(S_{1}\right)\left(\frac{p_{S A P}}{p_{A B S}}\right)+1}
$$

When external fluids permeate through the crack of the cement, the SAP will absorb fluid with an amount equal to $\mathrm{S}_{2} \mathrm{~m}_{\mathrm{A}}$, which will result in swelling of each SAP particle beyond its void and into the crack. The volume fraction of crack filled by $\operatorname{SAP}(\psi)$ is represented by:

$$
\begin{gathered}
\varphi=\frac{(\text { Swollen SAP vol. }- \text { dry SAP vol. })}{\text { crack vol. }} \\
=\frac{m_{A}\left(\frac{1}{p_{S A P}}+\frac{S_{2}}{p_{A B S}}\right)-m_{A}\left(\frac{1}{p_{S A P}}-\frac{S_{1}}{p_{A B S}}\right)}{w}=\frac{m_{A}\left(S_{2}-S_{1}\right)}{w_{p_{A B S}}}
\end{gathered}
$$

Substituting Eq. (3) into Eq. (4) and after rearrangement we will get

$$
\varphi=\frac{\alpha \mathrm{Cd}_{0}\left(\mathrm{~S}_{2}-\mathrm{S}_{1}\right)}{\mathrm{wp}_{\mathrm{ABS}}}\left(\sqrt[3]{\mathrm{S}_{1} \frac{\mathrm{p}_{\mathrm{SAP}}}{\mathrm{p}_{\mathrm{ABS}}}+1}\right)
$$

\section{Self-sealing tires}

Self-sealing tire is a special type of tire in which there is no leakage of air take place when nails puncture the tire. It consists of tire body, a sealant layer (or sealant material) with partition wall and inner rubber material (Fig. 22). The broken part of the tire is repaired automatically by self-sealing action of the sealant material. [70].

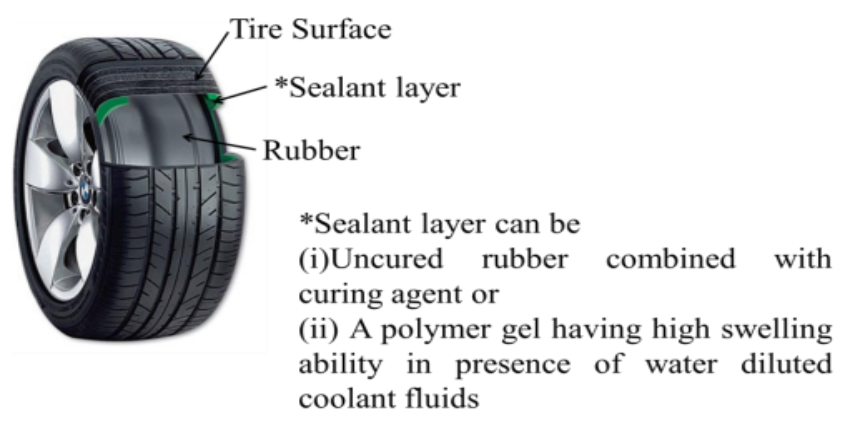

Fig. 22. Design of basic self-sealing tire.

The sealant material can be made in two ways. One is by using uncured rubber material combined with the curing agent. The curing agent cures the uncured rubber when nail punctures the tires and seals the puncture. Other one is by using superabsorbent polymer (SAP. The superabsorbent polymer expands when come in contact with fluid and become gel. This gel seals the puncture. The self-sealing tire based on above two sealant materials is described below:

\section{Self-sealing tire based on uncured rubber as sealant material}

The sealant layer is initially made up of the combination of specific quantities of a high and a low molecular weight curable butyl rubber, a curing agent for butyl rubber, a liquid polybutylene tackifier, a partially hydrogenated block copolymer of conjugated diene and styrene and carbon black (Table 4). When puncture 


\section{Advanced Materials Letters www. vbripress.com/aml}

occurs, sealant is cured which effectively heals most of the punctures one quarter inch in diameter or less in a vehicle tire at temperatures over the range of about $-28^{\circ} \mathrm{C}$ to $132^{\circ} \mathrm{C}$ without any significant loss of air [71-72] (Fig. 23).

Table 4. Compositions of chemically available sealant.

\begin{tabular}{l|c}
\multicolumn{1}{c|}{ Ingredients } & Parts by Weight (\%) \\
\hline High molecular weight, curable butyl rubber & 60 \\
\hline Low molecular weight, curable butyl rubber & 40 \\
\hline HAF carbon black & 50 \\
\hline SRF carbon black & 25 \\
\hline MT carbon black & 25 \\
\hline Tung oil & 5 \\
\hline Toluene & 483.5 \\
\hline Para-quinonedioxime & 2.5
\end{tabular}

*The Butyl rubber is basically a copolymer of $96 \%$ isobutylene and $4 \%$ isoprene. The average molecular weight of the high molecular weight butyl rubber is in the range of 100,000 to 300,000 . While, the molecular weight of low molecular weight butyl rubber is in the range of 10,000 to 30,000 . These two butyl rubber components are curable because of the residual unsaturation provided by the small isoprene content. The carbon black filler contributes strength to the sealant. The tung oil component is a processing additive. Toluene is a solvent for the uncured butyl rubber components. The paraquinonedioxime is a crosslinking agent which has to be oxidized to para-dinitroso benzene with a suitable oxidant, such as lead dioxide or benzoyl peroxide, to initiate curing [71-72].

(a)

(b)

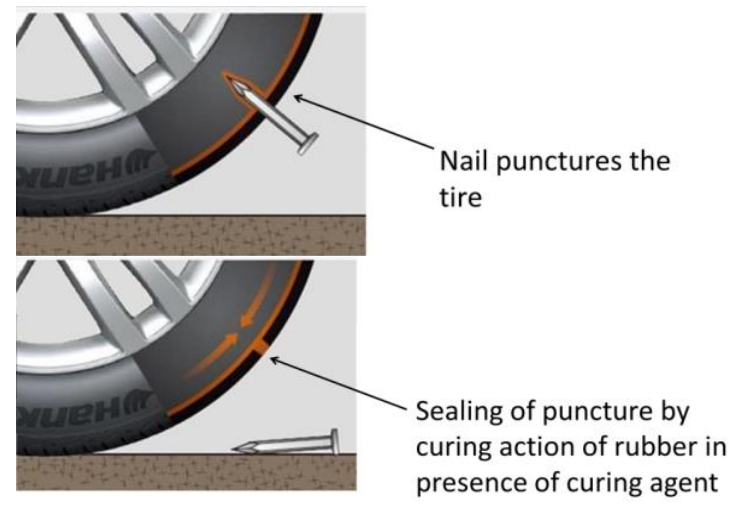

Fig. 23. Mechanism of self-repair in self-sealing tire based on curing uncured rubber.

\section{Self-sealing tire based on SAP as sealant material}

The structure of self-sealing tire based on SAP as sealant material consists of two rubber sheets with internal lattice. SAP particle which expands its volume on adding water is inserted into the lattice. This complete unit is adhere to the inside wall of the tire. A coolant fluid diluted with water is introduced to the polymer uniformly. In this system, SAP particles expand with the water diluted coolant fluids and become gel which creates high pressure in the lattice. (see Fig. 24). When the tire is punctured by the nail that is then removed, the pressure of the sealant due to polymer expansion repairs the puncture and prevents air leakage. Since the polymer gel get solidify when it comes in contact with air, it does not leak out from puncture hole [73].

The SAP sealant must be stable against all temperature ranges since automobileare used in both hot and cold atmospheres. Therefore, polymer called SunFresh (Sanyo Chemical Co. Ltd.) can be chosen as superabsorbent material. Its particles have diameters in the range from 150 to $710 \mu \mathrm{m}$. It absorbs about 400 times as much as water as its own weight. Further, it is stable against temperature and $\mathrm{pH}$ in the range from 4 to 10 . Water diluted coolant fluid must be stable at temperature from $-40^{\circ} \mathrm{C}$ to $+90^{\circ} \mathrm{C}$. So, mixture of $95 \mathrm{wt} . \%$ ethylene glycol and small amount of corrosion resistant fluid can be used as water diluted coolant fluid [73].

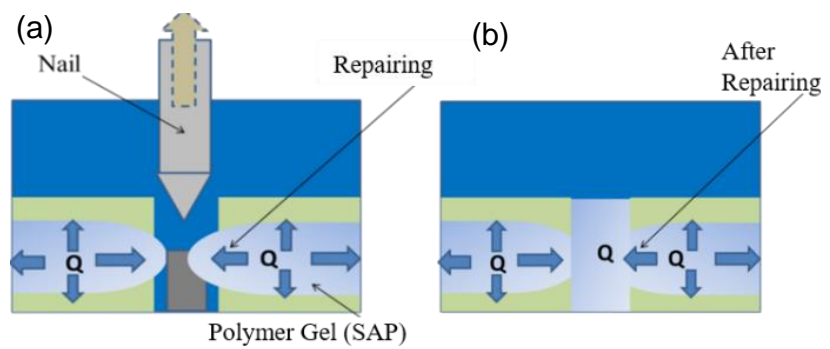

Fig. 24. Mechanism of self-repair in self-sealing tire based on polymer gel sealant [73].

\section{Conclusion}

In brief, synthetic materials having ability to response to stimuli epitomize one of the most interesting areas of scientific research. There are many exciting challenges in this field and vast numbers of opportunities in design and development of such type of smart materials. The objective of this review was to study and discuss various approaches, phenomenon and limitations in the selfsealing technology. Self-sealing spacecraft structures in the meteoroid environment are essential for successful completion of ambitious project of space travel. Further, Self-sealing fuel tanks in the fighter aircraft are indispensable for survival from the attack by the enemies. The conventional fuel tanks developed before World War II were not so much successful due to fuel losses, quality of rubber, etc. Researches are being carried out by various aviation agencies of the world to make the self-sealing fuel tank more reliable and efficient by improving their performance. The self-sealing approaches in the drug administration, cement crack repairing and automobile industry are also being applied to avoid catastrophic failure and provide a new direction to the modern technology.

\section{Keywords}

Sealant materials, vulcanized rubber, super absorbent polymers (SAPs), self-sealing fuel tank, self-sealing hemostatic syringe, self-sealing tires and concrete structures.

\section{Received: 04 March 2019}

Revised: 28 March 2019

Accepted: 22 May 2019

\section{References}

1. D'Anna, P.J.; Heitz, R.M.; Piechocki, J.J.; NASA CR-120 - Self-sealing Structures for Control of Meteoroid Hazard to Space Vehicles, October 1964.

2. "Self-sealing Structures for Control of the Meteoroid Hazard to Space Vehicles", Northrop Report NSL 62-132-7 (Part 11) March 1964.

3. "Self-Sealing Structures for Control of the Meteoroid Hazard to Space Vehicles", Northrop Report NSL 62-132-3, March 1963.

4. "Self-Sealing Structures for Control of the Meteoroid Hazard to Space Vehicles", Northrop Report NSL 62-132-4, June 1963.

5. "Self-Sealing Structures for Control of the Meteoroid Hazard to Space Vehicles", Northrop Report NSL 62-132-1, October 1962. (https://ntrs.nasa.gov/archive/nasa/casi.ntrs.nasa.gov/19630013321.pdf) 
6. www.gem-chem.net/rubbersilicone.html

7. Whitford, R.; Fundamentals of Fighter Design. Marlborough, Wiltshire. The Crowood Press Ltd., 2004, p. 153.

8. Federal Aviation Administration, Acceptable Methods, Techniques and Practices-Aircraft Inspection and Repair, AC43.13.1A, Change 3. U.S Department of Transportation, U.S. Government Printing Office, Washington D.C. 1988

9. https://www.aircraftsystemstech.com/2017/06/types-of-aircraft-fueltanks.html

10. "fuel tanks - henderson system - airscrew spinners - 1940 - 2064 - Flight Archive".

flightglobal.com.(https://www.flightglobal.com/pdfarchive/view/1940/1 940\%20-\%202064.html)

11. "the Ingenious Ju-88", Flight, 1940 (https://www.flightglobal.com/pdfarchive/view/1940/1940\%20$\% 203430 . \mathrm{html}$

12. Eger, E.; U.S. Patent 2401627, 1946.

13. Merrill, J.A.; U.S. Patent 2424701, 1947.

14. Balous, Miroslav, Jiř́íRajlich and Martin Velek. Messerschmitt Me 262 (in Czech/English). Prague: MBI, 1995. ISBN 80-901263-7-5.)

15. http://navyaviation.tpub.com/14018/css/14018_151.htm

16. Crawford, R.A.; Akron \& Ohio; U.S. Patent 2446811, 1948

17. Frolich, P. K.; L. S. Patent 2497123, 1950

18. U. S. Dept. Defense, Specification MIL-T-5578A, April 27, 1951.

19. Spenadel, L.; Good, R.; Synthetic Rubber for Self-Sealing Fuel Tanks, Industrial \& Engineering Chemistry, ACS Publications, 1959.

20. Gee, G.; TTans. Faraday SOC.; 1942, 38, 418

21. Rostler, F. S.; Rubber Aze.; 1946, 58, 585

22. Salomon, G.; Van Amerongen, G. J.; J. Polymer Sci., 1947, 2, 355.

23. Whitby, G. S.; Evans, A. B.; Paster-nack, D. S; Trans. Faraday SOC; 1942, 38, 269.

24. Whitby, G. S.; "Synthetic Rubber," Wiley, New York, 1954, pp689.

25. Dasher, P.J.; U.S. Patent 2438965, 1948

26. Detail Specification for the Tank, Fuel,Crash-Resistant, BallisticTolerant, Aircraft,MIL-DTL-27422D, 30 January 2007.

27. Min, O. J.; Hoon C. Y.; Man K. D.; Bae J. S.; "Fuel tank: A Study on Establishment of Performance Evaluation Criteria", Aerospace Proceedings of the $\mathbf{2 0 0 7}$ Spring Conference, pp.1-4.

28. Kim, H.Y.; Kim, S.C.; Lee, J.W.; Hwang, I.H.; Hue, J.W.; Shin, D.W.; Jung, T.K.; Ha, B.G.; Journal of the Korean Society for Aeronautical \& Space Sciences, 2010, 38, 477.

29. Francillon, R. J.; Japanese Aircraft of the Pacific War, Annapolis, Maryland: Naval Institute Press, 1995. (Originally published in 1970.)

30. Baugher, J.; Self-Sealing Fuel Tanks in the North American B-25 Mitchell, 2000. http://www.joebaugher.com/usaf_bombers/b25_3.html

31. North American's Flying Gun-The Story of the B-25 From Paper Airplane to Legendary Bomber, Jack Dean, Wings, 1993, 23, 4.

32. Cunningham, Wayne. The P-38 Lightning: Evolution of Speed and Climb Performance, October 15, 2006.

http://www.wwiiaircraftperformance.org/p-38/p-38-wayne.html.

33. SURVICE Engineering Company. "Advanced Autonomous SelfSealing Fuel Containment Technology Fact Sheet". http://www.survice.com/uploads/attachment/advancedautonomous-selfsealing.pdf (http://www.survice.com/uploads/attachment/advancedautonomous-self-sealing.pdf), accessed 1 May 2016

34. Shin, M.; Park, S.G.; Oh, B.C.; Kim, K.; Jo, S.; Lee, M.S.; Oh, S.S.; Hong, S.H.; Shin, E.C.; Kim, K.S.; Kang, S.W.; Lee, H.; Nature Materials, 2017, 16, 147.

35. Imran, A.B.; Seki,T.; Takeoka, Y.; Polym.; 2010, 42, 839

36. Lee, H.X.D.; Wong, H.S.; Buenfeld, N.R.; Cement \& Concrete Research; 2016, 79, 194.

37. Edvardsen,C.; ACI Mater. J., 1999, 96, 448.

38. Reinhardt, H.W.; Jooss, M.; Cem. Concr. Res.; 2003, 33, 981.

39. Wiktor, V.; Jonkers, H.M.; Cem. Concr. Compos.; 2011, 33, 763.

40. Buchholz, F.; Graham, A.; 'Modern Superabsorbent Polymer Technology' New York, John Wiley \& Sons. 1998, 154, 194.

41. Lee, H.X.D.; Wong, H.S.; Buenfeld, N.R.; Advances in Applied Ceramics.; 2010, 109, 296

42. Gonçalves, A.A.L.; Fonseca, A.C.; Fabela, I.G.P.; Coelho, J.F.J.; Serra, A.C.; Polym. Let.; 2016, 10, 248.

43. Lejcus, K.; S'pitalniak, M.; browska, J.; Polymers; 2018, 10, 271.

44. Chang, C.; Duan, B.; Cai, J.; Zhang, L.; Eur. Polym. J.; 2010, 46, 92.

45. Asadollahfardi, G.; Asadi, M.; Jafari, H.; Moradi, A.; Asadollahfardi, R.; Constr. Build. Mater.; 2015, 98, 305.

46. Raju, M.P.; Raju, K.M.; J. Appl. Polym. Sci.; 2001, 80, 2635.

47. Scognamillo, S.; Alzari, V.; Nuvoli, D.; Illescas, J.; Marceddu, S.; Mariani, A.; J. Polym. Sci. Part A Polym. Chem.; 2011, $49,1228$.
48. Kiatkamjornwong; Wongwatthanasatien, R.; Macromolecular Symposia, 2004, 207, 229.

49. Kang,S.H.; Hong, S.G.; Moon, J.; Cement and Concrete Research 2017, 97, 73

50. Lee, H. X. D.; Wong. H. S.; Buenfeld, N.R.; Advances in Applied Ceramics; 2010, 109, 296

51. Al-Nasra, M.; Self-sealing concrete mortar, concrete mortar mixed with super absorbent polymer MATEC Web of Conferences 120, 02002 , 2017.

52. Dubey, A.; International Journal of Research in Engineering and Applied Sciences; 2016, 6, 3.

53. Lee, H. X. D.; Wong. H. S.; Buenfeld, N.R.; Cement \& Concrete Research; 2016, 79, 194.

54. Mechtcherine, V.; Secrieru, E.; Schröf, C.; Cement and Concrete Research; 2015, 67, 52.

55. Lee, S.; Ha, K.; Jung, Y.; Jang, S.; Yeo, I.; KSCE Journal of Civil Engineering; 2014, 18, 1397

56. Lee, H. X. D.; Wong. H. S.; Buenfeld, N.R.; Concrete. Adv. Appl. Ceram.; 2010, 109, 296.

57. Snoeck, D.; van Tittelboom, K.; de Belie, N.; Steuperaert, S.; Dubruel P.; The use of superabsorbent polymersas a crack sealing and crack healing mechanism in cementitious materials. In Proceedings of the $3^{\text {rd }}$ International Conference on Concrete Repair, Rehabilitation and Retrofitting, Cape Town, South Afrcia, 3-5 September; 2012, pp.152157.

58. Gartner, E.; Tang, F.; Weiss, S.; J. Am. Ceram. Soc.; 1985, 68, 667.

59. Rha, C.Y.; Seong, J.W.; Kim, C.E; Lee, S.K.; Kim, W.K.; J. Mater Sci.; 1999, 34, 4653

60. Huber, K. J.; Phys. Chem.; 1993, 97, 9825.

61. Schweins, R.; Huber, K.; Eur. Phys. J. E.; 2001, 5, 117.

62. Lee, H.X.D.; Wong, H.S.; Buenfeld, N.R.; Adv. Appl. Ceram.; 2010, 5 296.

63. Al-Nasra, M.; Daoudb, M.; Taher, M.; Lebdeh, A.; American Journal of Engineering and Applied Sciences; 2015, 8, 659.

64. Al-Nasra, M.; American Journal of Engineering Research (AJER); 2014, 3, 132

65. Jensen, M.; Concrete International; 2013, 35, 48

66. Khushefati, W.; Healing of cracks in concrete, Department of Civil and Environmental 655 Engineering, Imperial College, University of London, PhD. Thesis, 2004.

67. Lee, H.X.D.; Wong, H.S.; Buenfeld, N.R.; Cement \& Concrete Research; 2016, 79, 194

68. Underwood, E.E.; Quantitative Stereology, Addision-Wesley, Reading, Massachusetts, 1970

69. Russ, J.C.; Dehoff, R.T.; Practical Stereology, Second Edition, New York, Plenum Press, 2001.

70. Yamagiwa, T.; Nakayama, K.; Kiyota, S.;Tanaka, A.; Makisaka, N.; Preprint of Society of Automotive Engineers of Japan, 1997, 976, 292

71. Stang et al., U. S. Patent. 3935893, 1976.

72. Kim et al. U.S. Patent 7607466 B2, 2009

73. Koshuke, N.; Shegio, I.; Manabu, C.; Xujing, C.; Tire with selfrepairing mechanism. JSME International, 2006, Series C, Vol. 49(2), pp.379-384

\section{Contributions}

1. Nand Kumar: He is the main author who wrote and drafted the complete manuscript.

2. Dibyendu Sekhar Bag: Under his guidance, whole manuscript was written. He gave the ideas of self-sealing approach in Fuel tanks, hemostatic syring, SAPs and self-sealing tyres.

3. Krishna Pratap Singh: He provided the idea of self-sealing approch in the spacecraft structures in the meteoroid environments. He drew all the colourful model figures related to self-sealing mechanism in the manuscript.

4. Akansha Dixit: She had compiled all the data related to Super Absorbent Polymers.

5. Shashank Mishra: He provided the important informations and data regarding self-sealing performance of Korean rotar aircraft fuel tank against gunfire projectiles

6. Durgesh Nath Tripathi: He provided all the relevant informations regarding the use of rubber in making advance composites.

7. Namburi Eswara Prasad: $\mathrm{He}$ is the head of our institution. $\mathrm{He}$ encouraged us and provided ample time and opportunity to write this review article successfully. 